Revista de Filosofía

ISSN: 0034-8244

https://dx.doi.org/10.5209/resf.65212

\title{
Actualidad de Heidegger en siete tiempos. Esbozos para un proyecto político
}

Daniel Calles Rittner ${ }^{1}$

Recibido: 25 de julio de 2019 / Aceptado: 10 de agosto de 2020

Resumen. El presente ensayo se propone dar cuenta de la actualidad del pensamiento de Heidegger desde una concisa y simple interpretación hermenéutica del contexto y la intencionalidad del pensador alemán en siete tiempos. Se aboga por una particular reinterpretación del proyecto político de Heidegger en el umbral de la postmodernidad.

Palabras claves: ser; Dasein; Sorge; historicidad.

\section{[en] Actuality of Heidegger in seven stages. Sketches for a political project}

\begin{abstract}
The current essay intends to express the actuality of Heidegger's thinking from a simple and concise hermeneutical interpretation (of context and intentionality) of the German philosopher in seven stages. This is also a call for an ethical reinterpretation of a particular Heidegger's political project in the midst of postmodernity.
\end{abstract}

Keywords: be; Dasein; Sorge; historicity.

Sumario: 1 . El ser; 2. La temporalidad; 3. La historicidad y el cuidado; 4. Los estados anímicos; 5. La economía de la destrucción; 6. Lenguaje y devenir; 7. La pregunta por la ética; 8 . Referencias bibliográficas.

Cómo citar: Calles Rittner, D. (2021): “Actualidad de Heidegger en siete tiempos. Esbozos para un proyecto político", en Revista de Filosofía 46 (2), 435-444.

1 Universidad Nacional Autónoma de México

rittner@políticas.unam.mx 


\section{El ser}

1927: en un mundo agitado por las ideologías proto-fascistas la filosofía está en crisis. En la historia del hombre no se ha tenido registro de una época tan turbulenta como el espíritu de la primera mitad del siglo XX. Del hombre brotan las más extremas pasiones sin pensarse a sí mismo, de aquí que la labor de la filosofía se comprenda como la más radical de todas las misiones históricas. Reflexionar sobre la crisis histórica del ánthropos en el mundo moderno tiene que situarse tan atrás como Platón y Aristóteles, en el origen de la pregunta por nuestra propia condición. Los griegos comprendieron este camino alrededor de la ousía, de un modo equivalente a la sustancia. El propio Platón, en el Sofista, definió la labor filosófica que disputa la realidad, entre aquellos que se aferran a la materia o a las formas, como una titánica lucha alrededor de la sustancia, “[...] gigantomachía perì tês ousías”, (2011, 246a) De aquí se entiende que el pensamiento se interpone siempre como una feroz frontera entre el eros y los cuerpos...

En el tempestivo siglo XX, entre la filosofía y la práctica política pareciera haber una suerte de impasse que impide el ingreso del individuo a la historia. Esto es sintomático de una atroz pérdida de la capacidad combativa de la razón del hombre moderno alrededor de esa estructura que Aristóteles definió formalmente como ousía en los libros IV y V de la Metafísica. En esta interpretación, la definición aristotélica remite a "[...] lo que es causa inmanente del ser de aquellas cosas que no se predican de un sujeto: así, el alma para el animal". (2011, 1017b). La filosofía intentó monopolizar, parcialmente, el discurso de esa lucha alrededor de la ousía en la forma de conceptos. Los daños colaterales fueron graves. Se destruyó de facto todo contenido esencial no planteado por los discursos platónicos y aristotélicos y, en la transición de la sustancia a los conceptos, los hombres dejamos de preguntarnos por el ser. Es así como, en ese agitado tiempo, en el ocaso de la tradición metafísica de Occidente, -en respuesta a los polos ideológicos de su tiempo- Heidegger donó al hombre, más que una obra, el principio de un camino: Ser y tiempo. En él, postuló del modo más radical la pregunta por el sentido del ser que toma el tiempo como su único horizonte de posibilidad (Heidegger 2014, p. 19). De aquí, emerge una diferenciación ontológica entre el ser y su ente, cuya intención no es otra que transparentar las múltiples formas de acceso del ente al ser, abriendo así la filosofía al encuentro con su misión histórica. De la pregunta por el ser de Heidegger se deduce la revivificación platónica de la autenticidad de lucha del pensamiento por el sentido de la sustancia en torno a una realidad concreta. No se trataba de la determinación esencial del ser en lo enunciado por Hegel como lo «inmediato»e «indeterminado»; si, en cambio, de dirigir la vista a la metódica interrogación sobre los posibles modos de ser de un ente desde la facticidad de la vida. Algo inusual y no previsto hasta entonces en toda la historia de la filosofía. Ante este enigma del ser, el pensador alemán buscó su desocultamiento histórico en una renovada ontología fundamental que ubica al Dasein como el campo habitual de una analítica existenciaria en la que el hombre mismo se pregunta por su autenticidad, siempre desde su irrevocable posición axiomática: estar-en-el-mundo. En Heidegger, Dasein sustituye la palabra hombre, porque ésta última implica tan sólo una posibilidad de ser del ente que somos nosotros mismos. Cuando el oriundo de Meßkirch precisa que «El planteamiento explícito y transparente de la pregunta por el ser exige la previa y adecuada exposición de un ente [del Dasein] en lo que respecta a su ser» 
(Heidegger 2014, p. 28), expone puntualmente la metodología con la que pretende dar respuesta a su propia pregunta. El ente es el vehículo de acceso al ser. [Da]-[Sein] es el binomio del lugar de la pregunta misma por el hombre y su ser desde la frontera de nuestra propia comprensión. Dasein se traduce entonces como el tránsito del ente al ser, es decir, de la apertura del hombre desde un emplazamiento concreto en el lugar del ahí $[D a]$, a su ser mismo que se descubre como pura posibilidad, [Sein] (Escudero 2016, p. 87).

\section{La temporalidad}

Contra el cogito ergo sum, contempla Heidegger la máxima de las dudas. No es la razón la esencia que define al ánthropos; sí en cambio la capacidad de percibir el tiempo y habitar en él a la vez que somos movidos por el tiempo. De modo que la percepción del tiempo, fundamentalmente la facultad de la contemplación humana de la finitud es un sentido, el cual tal y como Heidegger señala, es «[...] es aquello en lo que se mueve la inteligibilidad de algo» (2014, p. 175). La enunciación de ese algo es más que relevante. La propia condición del pensamiento está dada porque existe un medio para su desplazamiento. Existe un espacio para su inteligibilidad que nosotros percibimos como tiempo. Así, la temporalidad es la condición esencial de toda inteligibilidad, la fuente de todo entendimiento especulativo. Para su explicación Heidegger acudió a la relación entre el ser y el tiempo con el fin de aclarar la determinación conceptual del sentido del ser mismo. Se trata de una diferencia ontológica de grado con respecto a toda la historia de la filosofía que había olvidado la pregunta por el ser. Lo que se descubre en su lugar es una interpretación hermenéutica de la temporalidad cuyo carácter es enteramente móvil. Como Gadamer plantea «La analítica temporal del estar ahí humano en Heidegger ha mostrado en mi opinión de una manera convincente, que la comprensión no es uno de los modos de comportamiento del sujeto, sino el modo de ser del propio estar ahí» (Gadamer 2012, p. 12).

Pero la interrogación por el sentido del ser tiene para Heidegger una forma estructural comprendida como Dasein, como el lugar primero de la verdad del ser donde todo es vivido, experimentado y preguntado desde el ente que somos nosotros mismos. De un modo muy próximo a la potencia-acto (dynamis-energeia) aristotélico, Dasein es una estructura que pone en juego toda posibilidad ontológica en la que el ente parte de la realidad concreta de su haber y lo próximamente a su alcance para producir un horizonte de manifestación posible. Tanto de su ser como de su no ser. «El ser mismo con respecto al cual el Dasein se puede comportar de esta o aquella manera y con respecto al cual siempre se comporta de alguna determinada manera, lo llamamos existencia» (Heidegger 2014, p. 33). De aquí debe de comprenderse, muy tempranamente en Ser y tiempo, que estar-en-el-mundo implica siempre la inagotable resolución de un llegar-a-ser.

\section{La historicidad y el cuidado}

Comprender la existencia como Dasein implica un reculamiento del principio de objetividad de la historia moderna que presupone la interpretación y el ordenamiento 
de los fenómenos históricos en el marco particular de una estructura lógica y científica que determina el concepto del tiempo de acuerdo con sus propias tareas y finalidades. De aquí la necesidad de distinguir la conceptualización de la historia [Geschichte] de su ciencia histórica como Historia [Historie] (Heidegger 2014, p. 389). Heidegger se aleja de la interpretación doctrinal de una historia impersonal que solamente es accesible como objeto de una ciencia; en su lugar abre el hiato a una existencia del modo más personal y subjetivo que ubica al Dasein en el centro de una nueva narrativa histórica que se descubre como historicidad [Geshichtlichkeit]. Esta dimensión puede interpretarse como el horizonte de la temporalidad, (con las cualidades adheridas de extensión, movilidad, duración y persistencia) del hombre que, como intenta aclarar Heidegger, trasciende el problema de la historia misma. «El análisis de la historicidad del Dasein intenta mostrar que este ente no es tempóreo porque esté dentro de la historia, sino que, por el contrario, sólo existe y puede existir históricamente porque es tempóreo en el fondo de su ser» (2014, p.390). Contra el anclaje del pensar histórico-científico siempre en relación con el pasado, se descubre el sentido de una historicidad epocal como la «[...] totalidad de un ente que cambia en el tiempo» inscrita en el juego actuante de un devenir, ante lo cual el Dasein se comporta siempre fácticamente en relación con el futuro. Así, la pregunta por el ser del hombre se descubre como un proyecto histórico que experimenta y evade su finitud mediante el carácter resolutivo con lo posible.

El enraizamiento de la historicidad del hombre tiene lugar en el cuidado [Sorge]. El cuidado es el principal fenómeno de la existencia y la impronta del carácter humano que da cuenta de nuestros múltiples modos de ser. Sorge también puede comprenderse como empatía por el entendimiento especulativo de lo enunciado en la temporalidad. En el Heidegger de Ser y tiempo el cuidado es el radio de la perfección humana, lo que equivale a nombrarlo el ser del Dasein. Se trata, en todo caso, de la estructura que ordena las dinámicas humanas, -teóricas y prácticas-, como un modelo de procuración, en un anticiparse-a-si ante la existencia fáctica (Heidegger 2014, pp. 210-211), pues sólo en ese anticiparse a sí es que el hombre puede radicar su condición libre. Pero qué significa esta libertad, en tanto para Heidegger el cuidado es siempre un estar-en-medio-de. «El cuidado es siempre, sea privativamente, ocupación y solicitud» (Heidegger 2014, p. 212). Tal sentencia supone que la voluntad está siempre implicada como una relación entre una parte solicitante y otra parte diligente que asume la tarea de desplazar al ser a su ente como parte de una relación de sentido en el que ambas partes dependen, una de otra, para su entera realización. Como sugiere Trawny, el cuidado «es el indicador de la «totalidad» del Dasein» (2017, p.79). Esto descubre una tesis fundamental para nuestro tiempo presente: toda la historia política implica circunspección en el cuidado, dado que, si el hombre puede desplegar una historicidad propia con miras a un destino común [Geschick], esto descubre un proyecto político. De aquí que la apertura del hombre a su propia historicidad tenga que interpretarse como destino.

El nuevo emplazamiento ontológico donado por Heidegger es mejor comprendido como una fenomenología hermenéutica que toma la vida cotidiana y su medianía como su espacio de significación histórica abierta a una constante interpretación y resolución en la que el Dasein está siempre confinado a un mundo circundante [Umwelt $]$ y por lo tanto a un destino singular. En los esbozos de Ser y tiempo, se trata de una historia muy particular, propia a cada uno: «El Dasein tiene fácticamente en cada caso su historia y puede tenerla porque el ser de este ente se halla constituido 
por la historicidad» (Heidegger 2014, p. 398). Lo que significa que el destino, como proyección del hombre al futuro, es la historicidad originaria de todo Dasein. La historicidad debe ser pensada como una inversión del valor de la historia: La historia hunde sus raíces no en la conexión del presente con el pasado, como sí en el futuro brotante (Heidegger 2014, p. 399). La finitud es el campo de la historicidad auténtica declarada por Heidegger. La actualidad del pensamiento de Heidegger es tal que la filosofía postmoderna sólo puede construirse desde ahí, es decir: desde las experiencias singulares de lo común e inmediato que asumen la temporalidad como el marco para la comprensión de la realidad en función de sus posibilidades de crecimiento, renovación y finitud.

Con lo anterior, se resalta un aspecto desbordante en Heidegger: la proyección de toda posibilidad ontológica del Dasein remite al núcleo de su propia finitud. La apertura del ente del hombre a su ser está cargada de una preconcepción en la escala de lo más impersonal: la muerte. En esta arqueología psíquica, por llamarla de algún modo, si el cuidado expresa la posibilidad de comprender la existencia como un todo-estructural; la muerte es su facticidad negativa, el término y cancelamiento de toda posibilidad del Dasein. El hombre es un ser-para-la-muerte porque está permanentemente vuelco para la muerte. «La muerte es la posibilidad más propia del Dasein. Estar vuelco a esa posibilidad le abre al Dasein su más propio poder-ser, en el que su ser está puesto radicalmente en juego» (Heidegger 2014, p. 279). Lo que el pensador está diciendo es que sólo frente a la posibilidad de su propia finitud el ser reivindica su singularidad en la historia. «Para Heidegger, la «muerte» es el «poder» por el que el Dasein se reconoce a sí mismo[...]» (Trawny 2017, p.81). De la constante anticipación a la muerte resulta una oikonomía de la existencia en la que el hombre especula con su propia finitud. Algo ya muy cercano a una economía negativa del deseo que ancla la angustia [Angst] como la disposición afectiva fundamental en la vida del hombre. Se trata de un repliegue del Dasein a sí mismo que urde el cuidado de sí y de lo común frente a la impropiedad de la muerte.

Así, la filosofía personalísima de Heidegger se sostiene en el firmamento griego de la askesis [ejercicio] desde el cual el propio Platón, en Fedón, resume la filosofía como una preparación para la muerte (Platón 2010, 68a). En su sentido más práctico y genuino, existir consiste, como radia Nietzsche desde la aurora de su pensamiento, en realizarse a través de la práctica y comprender la toda la vida como una obra, en ejercitarse en llegar a ser lo que se es. "iAnte todo y sobre todo las obras! Esto significa: ipráctica, práctica y más práctica!» (Nietzsche 2015, I-[22] p. 76 ). Al propio Nietzsche Heidegger atesta ¡Caminos no obras! Mas en el caso de Heidegger, el lugar de la filosofía no consiste, como en Platón, en la radicalidad de una vida ascética como vía de acceso al destino metafísico; sino al revés: una radical metafísica que accede a la vida por medio de una arqueología del ser que instala su finitud como el centro de su acción.

\section{Los estados anímicos}

En el pensamiento de Heidegger, los estados anímicos resultan fundamentales para el esclarecimiento del comportamiento del hombre en el mundo y su temporalidad. En Ser y tiempo la angustia que procede al ser-para-la-muerte se esclarece como la «disposición afectiva fundamental» y en consecuencia, como el «modo inmanente de 
la aperturidad del Dasein». Esta huida del hombre de sí mismo, revela el carácter de su propia libertad (Heidegger 2014, p.206). El hombre es arrojado a una espacialidad exterior, fuera de su casa primigenia y al estar abierto al mundo en la historia, el hombre interpreta su identidad, se aísla, evade, actúa y esclarece su carácter destinal. Es a lo largo de este proceso que le son reveladas sus posibilidades de ser como parte de un juego de finitud ordenado por los horizontes existenciales del aniquilamiento y la transformación.

En mucho, gracias a Heidegger se sabe muy bien ahora, en los tiempos postmodernos, que la historia es conmovida por las disposiciones anímicas. Posterior a la publicación de Ser y tiempo, desde las lecciones del invierno 19291930 recabadas en Los conceptos fundamentales de la metafisica, el proyecto de su filosofía se comprende como la radical enunciación afectiva contra el aburrimiento [Langeweile] que adormece al Dasein del encuentro con su destino histórico. De aquí la auténtica propuesta política de Heidegger. A lo largo de la historia moderna las tonalidades anímicas, tales como la angustia y el aburrimiento, son los vehículos de explotación y movilización del individuo que desde su estado de aburrimiento es desplazado al estadio de la alienación de la espacialidad colectiva. La angustia y el aburrimiento tienen que servir para el ligamento histórico del hombre en las estructuras ontológicas del cuidado. Heidegger, -para quien la historia ha desplazado al Dasein a un des-raizamiento histórico y a una masificación política-democrática que reduce a todos los entes a una indiferente igualdad-busca, en un contrasentido, el genuino despertar del Dasein de su aburrimiento epocal como el signo del un estado de ánimo global.

La interpretación radical de los estados anímicos realizada por Heidegger expone una fisura histórica en el pensamiento filosófico moderno que evade la totalización ideológica englobada en los procesos de la Ilustración y el idealismo alemán. Lo que se descubre anuncia un estado de las cosas que designará el carácter epocal de una nueva era como una inagotable búsqueda del sentido. En la opinión de Sloterdijk, la indagación de los estados anímicos en Heidegger descubre una nueva arqueología filosófica sustancial para la comprensión de la relación entre el hombre y su tiempo. «Quien quiera abordar a los seres humanos de modo más profundo que aquel en lo que consiguieron la filosofía tradicional y su continuación en la Ilustración tiene que colocarse en este nivel preobjetivo y comenzar desde él el trabajo con los estados de ánimo. Esto nos acerca a la vez al gran polo del acontecer histórico, dado que un estado de ánimo puede ilustrarnos no sólo sobre la situación de la historia, sino también sobre su curso y su meta» (Sloterdijk 2018, pp. 141-142).

\section{La economía de la destrucción}

No hay duda alguna que el gran pensamiento de Heidegger estará siempre imputado por la banalidad del prejuicio de su antisemitismo del modo más abyecto y vulgar, comenzando por la aniquilación del sentido ético en su discurso; pero también como denuncia Nancy desde la puntual lectura de los Cuadernos negros, por su desprecio oculto al Nacional Socialismo Alemán. Esta bipolaridad en el pensamiento del mago de Meßkirch relata la inscripción de una política de identidad del Dasein histórico que, en el modo de su autor de sustraerse al relato político y de ordenar su historicidad bajo las huellas gramaticales de pueblo y destino resalta el carácter negativo de una 
escatología histórica. ¿No es esta la huella de un proyecto eminentemente político? Si desde Ser y tiempo se precisa que la muerte pone en juego al Dasein, es porque a través de las disposiciones anímicas se configura un sentido de identidad del cuidado humano que pone al ser en el juego de la historia y del destino. Es decir, en la lógica temprana del acontecimiento de Heidegger, el Dasein eyecto, siempre errante, es enviado desde un primer origen a través de la historia al encuentro con su propio destino. De aquí que toda la errancia en el pensamiento de Heidegger se descubra como reunión. La lógica que de aquí procede es una economía de la destrucción que, según Nancy de un modo insostenible en Heidegger requirió de la «destructividad para liberar otro comienzo» (Nancy 2019, p. 40). Pero la destrucción en Heidegger tiene dos sentidos. El primero, inadmisible, anclado en el juicio ético que la razón impone sobre el espíritu trágico del Dasein histórico y en el que se expresa la errancia histórica de su pensamiento. El segundo, emancipatorio, se esboza desde la genuina destrucción del sentido ontológico del ser que se pregunta por la autenticidad del hombre y el camino a seguir.

Al título de Ser y tiempo bien podría adherirse después de un largo silencio: ...destrucción, pues el camino de Ser y tiempo, terreno primordial en el andar de Heidegger, es el principio de un desmontaje, inacabado, de la tarea del pensamiento sobre el origen de Occidente. El eco de la sentencia de Parménides «el ser es», tiene que escucharse hasta nuestros días como el acontecimiento originario sobre el cual Heidegger persistirá a lo largo de su vida en la edificación de una nueva ontología capaz de distinguir entre el ser y la existencia. Pero como afirmaría éticamente Levinas, ante los terrores de la modernidad, la posmodernidad urgió transitar de la existencia al existente. En esta diferenciación se admite, como señaló Derrida, la marca de una ausencia, del olvido de la diferencia entre el ser y la existencia que demarcan la separación entre presente y presencia. (Derrida 2018, p. 58). Si el ser es siempre posibilidad y en su realización fáctica siempre hay algo que no ha llegado a ser, la desconstrucción planteada por Heidegger invita a pensar el ser desde su falta y olvido. En La palabra de Anaximandro de 1946 dice Heidegger, «El olvido del ser, forma parte de la esencia misma del ser velada por el propio olvido» (Heidegger 2010, p. 271). En tanto para Platón la teoría de la segunda navegación indica el camino al lugar de la verdad que, desde la ilusoria realidad del mundo de los sentidos, se persigue a través de la reminiscencia de la multiplicidad de los entes hasta su reunión en unidad del Bien; para el pensador alemán el camino de la reminiscencia es invertido desde la multiplicidad de lo ente hacia el abismo del ser singular y concreto en el extravío histórico. De modo que preguntarse por el ser es preguntarse por uno mismo como la tarea más radical del pensamiento.

A partir de aquí, las crónicas del Dasein posmoderno más que agotarse en la sentencia de Parménides se intensifican en una multiplicidad de regiones ontológicas como campos de cuidado, de ocupación y de co-pertenencia que exhortan a la producción y a la transformación del mundo ante la emergencia de la vida fáctica. Para Heidegger, se trata de una erosión del sentido del ser que proviene desde el acontecimiento del primer origen de Occidente anclado en la antigua Grecia y se eyecta hacia el encuentro con su destino en la historia; de modo que la facticidad del Dasein experimenta, en su condición de arrojo [Geworfenheit] desde el arje, múltiples posibilidades de enraizamiento, crecimiento y destrucción. El Dasein es previsto por el maestro de Friburgo como la escapatoria ontológica a la deriva histórica e insostenible del Occidente. Ante el cálculo de la racionalidad instrumental, 
la técnica y la sociedad de masas, -Heidegger, gravemente influido por el astro de Nietzsche-, reclama una nueva autonomía, no del juicio moralmente obstruido de una sociedad decadente, como sí de una singularidad propia, auténtica y resolutiva asida a un nuevo mito que invita a avisar nuevos horizontes humanos en el espectro de su temporalidad. Mito en el cual de acuerdo con Zimmerman y Escudero se explica el Dasein como: la lucha y huida contra la caída en la impropiedad, la afirmación radical del individuo y el reconocimiento de la finitud humana a la confrontación y la transformación de uno mismo (Escudero 2016, p. 18).

\section{Lenguaje y devenir}

El mundo y su significación están dados por la intencionalidad del lenguaje. «El discurso es existencialmente co-originario con la disposición afectiva y el comprender», (Heidegger 2014, p. 179). Heidegger se resiste al sentido clásico y politológico del Logos como el hábitat entre los hombres; en su lugar considera que el lenguaje tiene un contenido esencialmente temático cuyo fundamento ontológico es el discurso. Es decir, la teoría del lenguaje de Heidegger tiene un sentido dúplex. Hay un discurso interior y ontológicamente anterior al lenguaje: «La exteriorización del discurso es el lenguaje» (Heidegger 2014, p. 180). Por lo tanto, el discurso es un sentido interior, -idea que confronta la noción del intelecto cartesiano como el canal de acceso al mundo-que permanentemente forja y articula sus significantes mediante la proyección del lenguaje con todo lo que está dispuesto en el mundo a la mano. Aquí el lenguaje tiende a afirmarse en la historia humana mediante regiones ontológicas enunciadas como estar-en-el-mundo. Se trata de estructuras de emplazamiento que se definen por su contención técnica en un lenguaje, por ejemplo: tradiciones, escuelas de pensamiento, oficios, etc. Mas Heidegger es también lo suficientemente cauto, como lo fueron los antiguos filósofos frente a los sofistas, para reconocer que el lenguaje, una vez exteriorizado, está constantemente expuesto a su desvanecimiento frente a las palabras-cosas que carecen de un significado duradero, de un modo próximo a la doxa platónica y al prejuico.

Para Heidegger, de acuerdo con el párrafo 12 de Ser y tiempo, este carácter del Dasein se expresa en el fenómeno unitario de estar-en-el-mundo, lo que equivale a una permanente movilidad del sentido del ser como un «estar dentro de» (Heidegger 2014, p. 75). Es decir, todas las cosas que se encuentran en el mundo participan en el modo de una coexistencia ontológica que Heidegger enuncia como categoriales. En el mundo hay entes, sea un adulto, un niño, pero en su interior hay un existencial, algo que se expresa como un significante y que tiene un carácter fáctico, un obrero, un enfermero, un profesor, un matemático etc. (Heidegger 2014, p. 77). Desde aquí Heidegger deduce que el carácter fáctico del Dasein como estar-en-elmundo tiene una condición intramundana. Por ejemplo, el profesor es también un padre, un amigo, un hijo, un poeta que como dirá Heidegger, se trata de un ente que comparece en su propio mundo a la vez que habita varios mundos. Siguiendo las huellas del eterno retorno de Nietzsche, el pensador alemán precisa que todo el fenómeno de la historicidad es incomprensible si se sustrae del poder del Dasein de proyectarse a sí mismo dentro de estas estructuras del lenguaje que expresan su ritmo y continuidad en la historia. Pues toda la historia se revela en la repetición. Estas tradiciones suponen para Heidegger el carácter del destino [Schiksal] expuesto 
a sus propias contrariedades en las que los hombres tienen que trabajar en repetirse. «Definiremos la repetición como el modo de resolución que se entrega a sí misma [una posibilidad heredada] y mediante el cual el Dasein existe explícitamente como destino» (Heidegger 2014, p. 399).

Remarcando el itinerario de la agenda histórica de Heidegger, quien constantemente se ocupa de un Dasein arrojado a la historia al encuentro con su propio destino, la lógica postmoderna, por efecto de un redireccionamiento ético, ha suplantado la peligrosa misión histórica del destino del ser, adherida al pensamiento de Heidegger por las paradojas del sentido de la intersubjetividad en el puro devenir que abren al Dasein a un nuevo horizonte de comprensión temporal. En el pensamiento postmoderno el sentido del ser es lo que deviene. Esta significación es magistralmente comprendida por Deleuze en la lectura de Lewis Caroll, (1levado de la mano de Nietzsche): «Tal es la simultaneidad de un devenir cuya propiedad es esquivar el presente. En la medida en que se esquiva el presente, el devenir no soporta la separación ni la distinción entre el antes y el después, entre el pasado y el futuro. Pertenece a la esencia del devenir avanzar, tirar en los dos sentidos en la vez: Alicia no crece sin empequeñecer, y a la inversa» (Deleuze 2016, p. 27). Mujeres, hombres y otras denominaciones genéricas postmodernas, somos todos espectros de una potencia temporal que constantemente esquiva el presente y resolvemos nuestra existencia fáctica mirando al pasado y al futuro simultáneamente. De aquí que el destino, enraizado en el futuro, sea sustituido por la idea del juego azaroso del devenir, porque la existencia concreta es siempre la resolución de una posibilidad que entre tantas ha sido llevada al acto. Quizá el enfermero quiso ser médico o el profesor político, pero circunstancias complejas y cambiantes han orillado al Dasein a una resolución fáctica que de ningún modo puede asegurarse como el presente ideal o necesariamente deseado.

\section{La pregunta por la ética}

Es innegable que el proyecto humanístico no es primordial en el pensamiento del Heidegger temprano. Al menos hasta la redacción de la Carta sobre el humanismo (1947) no hay ningún indicio de que así lo sea. La sustitución genérica del hombre por el concepto de Dasein refleja que, en su condición de ente, el hombre mismo es una modalidad del ser. De aquí debe de inferirse que toda la filosofía de Heidegger queda de algún modo suspendida en la historia por su propia neutralidad. Sin embargo, desde Heidegger la filosofía postmoderna reclama a su encuentro fenomenológico un registro de las condiciones materiales que dan cuenta de la necesidad de una antropología filosófica que bien se inscribe en la órbita del interés kantiano de la Antropología en sentido pragmático. ¡Sí! es posible preguntar por el hombre desde Heidegger, pero esto remite a una diferencia de grado. Quizá habría que preguntarnos si como plantea el profesor de Friburgo que el sentido del ser es producto de una tematización de la existencia (del Dasein personificado mediante distintas formas de estar-en-el-mundo), o tal y como propone su discípulo Levinas que el ser está implicado siempre como exterioridad y que «La tematización no agota el sentido de la exterioridad» (Levinas 2016, p. 340).

Reformular el sentido del ser como una exterioridad implica que el ser mismo sea capaz de expresar su plenitud solamente al reconocerse en el otro. ¿O hay mejor manera de interrogarse a sí mismo? En este caso, la radical temporalidad del sentido 
del ser que esta singularidad existencial llamada Dasein prefigura, invoca por sí misma el influjo de una ética inmanente. Toda singularidad del Dasein se topa con la otredad. Sea la otredad de una idea, un ente o un afecto, se trata siempre de un encuentro con aquello que le potencializa como cuidado o con aquello que le aniquila en la frontera de lo impersonal y a partir del cual el hombre justifica su plena libertad entre la necesidad y la muerte.

\section{Referencias bibliográficas}

Aristóteles. (2014). Aristóteles, Madrid, Gredos.

Deleuze, G. (2016): Lógica del sentido, Barcelona, Paidós.

Derrida, J. (2010): Márgenes de la filosofía, Madrid, Cátedra.

Escudero, J.A. (2016): Guía para la lectura de Ser y tiempo, vol. I., Barcelona, Herder.

Gadamer, H.G. (2012): Verdad y método, vol. I, Salamanca, Sígueme.

Heidegger, M. (2010): Caminos de bosque, Madrid, Alianza.

Heidegger, M. (2014): Ser y tiempo, Madrid, Trotta.

Levinas, E. (2016): Totalidad e infinito, Salamanca, Ediciones Sígueme.

Nancy, J.L. (2019): Banalidad de Heidegger, Madrid, Trotta.

Nietzsche, F. (2015): Aurora. Pensamiento sobre los prejuicios morales, Madrid, Biblioteca Nueva.

Platón (2010): Platón. vol. I., Madrid, Gredos.

Platón (2011): Platón. vol. III., Madrid, Gredos.

Sloterdijk, P. (2018): ¿Qué sucedió en el siglo XXI?, Madrid, Siruela.

Trawny, P. (2017): Martin Heidegger. Una introducción crítica. Barcelona, Herder. 